\title{
Exploring the Environmental Feasibility of Integrated Sanitation Systems for Uganda
}

\author{
Miria F. Agunyo"1, Jens Born', Eleanor Wozei ${ }^{3}$, Bernd Moeller ${ }^{4}$ \\ ${ }^{1}$ Department of Energy and Environmental Management, Europa Universität Flensburg, Munketoft 3b, \\ 24937 Flensburg, Germany \\ e-mail: anomotmiria@gmail.com \\ ${ }^{2}$ Mechanical Engineering, Process Engineering and Maritime Technologies, Kanzlei Str. 91-93, \\ 24943 Flensburg, Germany \\ e-mail: jens.born@hs-flensburg.de \\ ${ }^{3}$ Department of Engineering and Environment, Uganda Christian University, Bishop Road, P.O. Box 4, \\ Mukono, Uganda \\ e-mail: ewozei@ucu.ac.ug \\ ${ }^{4}$ Department of Energy and Environmental Management, Europa Universität Flensburg, Munketoft 3b, \\ 24937 Flensburg, Germany \\ e-mail: bernd.Moeller@uni-flensburg.de
}

Cite as: Agunyo, M. F., Born, J., Wozei, E., Moeller, B., Exploring the Environmental Feasibility of Integrated Sanitation Systems for Uganda, J. sustain. dev. energy water environ. syst., 7(1), pp 28-43, 2019, DOI: https://doi.org/10.13044/j.sdewes.d6.0217

\begin{abstract}
In urban areas of Uganda, management of waste which consists of at least $70 \%$ organic content is accomplished by collection and disposal in landfills, resulting in emission of landfill gases among other impacts. Meanwhile, the limited number of wastewater and sludge treatment plants makes further management of sewage and faecal sludge generated from urban areas a major challenge. Thus, integrated sanitation systems which consider combined management of organic waste streams, i.e., bio waste, animal waste, sewage and faecal sludge, are proposed. The sanitation systems consist of a combination of anaerobic digestion and other technologies such as composting, incineration among others. Moreover, the systems also promote resource recovery in the form of biogas and organic fertilizer. The environmental feasibility of the integrated sanitation systems was investigated using life cycle assessment method. The results indicated that resource recovery contributed to the environmental feasibility of these sanitation systems. The more resources that were recovered from the sanitation systems, the lower the environmental impact.
\end{abstract}

\section{KEYWORDS}

Environmental feasibility, Integrated sanitation systems, Life cycle assessment.

\section{INTRODUCTION}

Management of waste is still a major challenge in urban areas of most Sub-Saharan African countries, where city or municipal authorities who are mandated to ensure waste management are often limited by availability of relevant financial resources. Generally, management of waste which may consist of at least $50 \%$ organic content will include

* Corresponding author 
collection from different locations and disposal at landfills. This approach results in environmental impacts due to emission of Greenhouse Gases (GHG) and leachate which contaminates ground water in addition to other health and livelihood related impacts $[1,2]$.

The future increase in population in Africa, which is projected to result in at least $58 \%$ urbanization by 2050 , can only exacerbate the problems of waste management if proper measures are not considered. The situation in Uganda does not vary much from the regional trend in most of the mentioned aspects. In Kampala and most major towns in Uganda, waste is collected for disposal at the landfills and yet the waste consists of at least $70 \%$ organic content. In terms of urban sanitation management, Uganda has sewerage coverage of only $10 \%$, allowing for treatment of wastewater in centralized treatment plants. Bearing in mind that onsite sanitation facilities consisting of pour flash toilet systems connected to septic tanks and pit latrines are commonly used, further management of sewage and faecal sludge is necessary. However, currently Uganda only has 20 sludge treatment plants, highlighting the gap in sanitation management $[3,4]$.

With a current birth rate of $3.24 \%$, Uganda's population is expected to increase from 40 million in 2017 to at least 100 million in 2050. This will result in an annual urbanization growth estimated at $5.43 \%$, which is much higher than that of the Sub-Sahara African region at $3.67 \%$ and Africa as a whole, estimated to be $4 \%$ per year $[5,6]$. Such a scenario would put more pressure on the already limited service delivery in terms of sanitation since population increase is not at par with necessary infrastructural development [6, 7]. Developing a holistic approach to managing organic residues, particularly integration of sanitation and organic solid waste management services already suggested in literature, could be a solution for urban areas of Uganda [8,9].

The integrated sanitation systems approach is based on the environmental sanitation approach, where management of human excreta, solid waste and wastewater among other aspects is considered. In this paper, the proposed integrated sanitation systems consider combined management of organic waste streams, i.e., sewage and faecal sludge, animal waste, bio waste and wastewater effluent. The proposed systems consist of two main objectives, i.e., management of organic waste streams and resource recovery. A combination of Anaerobic Digestion (AD) and other technologies such as composting, incineration, solar drying, etc. are considered for the integrated sanitation systems. Applicability of the proposed integrated sanitation systems is envisioned in peri-urban and urban areas of Uganda, especially in housing estates, institutions of learning, health facilities, industries, towns and cities. A set of criteria for consideration of the integrated sanitation systems is proposed and these include: location in urban areas, demand for environmental sanitation services with a focus on management of organic waste streams and existing dependent population size of at least 1,000 people. Moreover, since different stakeholder groups can be expected during the management of the various organic waste streams, cooperation between the groups is a crucial criterion.

The integrated sanitation system approach is not necessarily a new phenomenon given that the whole concept has been promoted for at least two decades and can be traced back to the overarching approach of environmental sanitation $[10,11]$. Over time, the environmental sanitation approach, which is quite broad has been redefined with the help of guiding principles such the "Bellagio Principles" that additionally enable the sanitation challenges to be managed within sizeable domains, i.e., household, neighborhood, community, town, district, catchments, and city [8, 12].

With reference to the description of integrated sanitation systems in this paper, practical examples include management of organic solid waste and wastewater and such projects have been installed in Wastewater Treatment Plants (WWTP) of mostly developed countries. Such systems have been promoted in some cities with the objective of managing waste resources, while additionally recovering resources thus, some of these cities have been "coined" sustainable/smart cities [9, 13]. In developing countries, 
examples of the integrated sanitation systems have been mostly practiced in solid waste management, where a $3 \mathrm{R}$ hierarchy of solid waste management is generally promoted based on the 3R principle of reduce, reuse and recycle. Moreover, other examples of integrated waste management include mainly the management of wastewater and to a small extent solid organic waste using Eco-San and bio-latrine systems [2, 14].

Despite having practical examples of integrated sanitation systems, documented evidence of environmental feasibility assessments for such systems can mainly be traced in developed countries and a few in developing countries [15, 16]. Meanwhile, particularly for the case of Uganda, the few documented environmental feasibility studies highlight the utilization of particular technologies such as composting for the management of solid organic waste or bio-latrine/ecosan systems for management of wastewater and certain organic waste streams $[17,18]$. However, with reference to the integrated sanitation system approach suggested in this paper (combined management of various organic waste streams), no studies assessing the environmental feasibility have been documented.

Given that the proposed integrated sanitation systems could be considered a solution for the management of organic streams for urban areas in Uganda, it is only prudent that the environmental feasibility of such systems is assessed [19]. Therefore, it is against this background that the environmental feasibility of the proposed integrated sanitation systems is investigated using the Life Cycle Assessment (LCA) method. By carrying out LCA, an overview of the environmental aspects of the sanitation systems over the whole life time can be analyzed while allowing for comparison of systems [20].

\section{MATERIALS AND METHODS}

Assessment of the environmental feasibility of the sanitation systems proposed in this study was carried out using LCA.

\section{Life Cycle Assessment}

This is a technique for assessing the environmental aspects and potential impacts associated with a product or process by:

- Compiling an inventory of relevant inputs and outputs of a product system;

- Evaluating the potential environmental impacts associated with those inputs and outputs;

- Interpreting the results of the inventory analysis and impact assessment phases in relation to the objectives of the study [20,21].

Generally, investigation of the systems' performance with reference to different points of view such as material and energy requirements, environmental impacts and ecological footprint is carried out during the assessment. Therefore, a range of specific and selected environmental impacts are assessed [22, 23]. LCA as a tool has been extensively applied for environmental assessment under the broad themes of design for the environmental purposes, marketing claims and Eco labels, government policy, in addition to water and sanitation system analysis [24, 25]. A typical LCA study consists of four main stages as summarized in Figure 1.

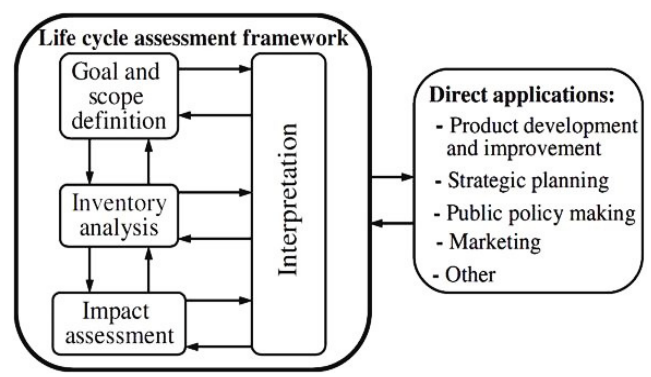

Figure 1. Stages of LCA (Source: [21]) 


\section{RESULTS}

To fully appreciate the assessment of integrated sanitation systems using LCA, a case study is used to allow for an empirical inquiry that investigates the phenomenon within a real life context [26].

\section{Case study area}

Uganda Christian University (UCU) is located in Mukono town and like most institutions in Uganda, the University is mandated to manage waste generated from the campus. The University has its own activated WWTP which treats wastewater from various source points within the University and the plant currently operates at half its capacity, i.e., treats $160 \mathrm{~m}^{3} /$ day of wastewater. Plastic waste generated is sorted and recycled, while kitchen waste is used as animal feed by local farmers neighbouring the University. A remnant portion of solid waste is either incinerated at UCU or disposed of at Mukono Municipal landfill, which is located about $7 \mathrm{~km}$ away from the University.

UCU currently experiences difficulty in the final disposal of sewage sludge from the WWTP. About $70 \%$ of the partially stabilized sewage sludge is left in lagoons which are located at the WWTP, and this poses a major disposal challenge. The remnant $30 \%$ of the partially stabilized sewage sludge is used as soil conditioner on the University sports field, while a portion of the conditioner is also used by interested local farmers neighbouring the University. Besides, UCU heavily depends on firewood for cooking and is interested in utilizing cleaner energy sources such as biogas. In the University's 6 year strategic plan (2012-2018), it is proposed that biogas could be produced by management of organic waste streams such as sewage sludge [27].

In support of this proposal, UCU envisions the use of cow dung from her farm as an additional substrate for the biogas production process.

Worthy of mention is the absence of a centralized WWTP/sewer networks to ensure proper management of wastewater and sewage sludge. Moreover, the Municipality also lacks a faecal sludge treatment plant, which would be used for further treatment/management of faecal sludge. Thus, the absence of such facilities implies that a major challenge exists in further management of sewage and faecal sludge generated from onsite sanitary facilities. These facilities may include pour flush toilets connected to septic tanks or pit latrines. The sanitary facilities mentioned are commonly used in homes, businesses or institutional settings within the Municipality [28]. Interested customers would have to consider hiring cesspool emptiers or manual emptying and semi-mechanized equipment, i.e., gulpers to transport the sludge to the nearest treatment plants, which are located in Kampala at least $22 \mathrm{~km}$ from Mukono. In dire conditions, illegal disposal of sewage sludge from septic tank systems and faecal sludge from pit latrines might be practiced, resulting in environmental degradation and negative health impacts. Bearing in mind that the WWTP at UCU operates at half its capacity, opportunities exist for possible management of the sewage and possible faecal sludge from neighbouring areas in Mukono. Therefore, with reference to this background, focus is drawn to the management of organic waste streams generated from UCU and neighbouring areas within Mukono town. The organic waste streams considered for management include sewage and faecal sludge, animal waste, bio waste and wastewater effluent.

UCU experiences a major challenge in the final disposal of sewage sludge from the WWTP and yet opportunities exist where combined management with other organic waste streams, i.e., cow dung, kitchen waste and faecal sludge could occur. Combined management of the waste steams would contribute to a circular economy through resource recovery in form of biogas and organic fertilizer, highlighting the key aspects of an integrated sanitation system approach as a viable option. Given that combined 
management of different organic waste streams is considered, variable technologies/processes would be required to manage the waste.

Hence, a combination of AD technologies and other technologies/processes, i.e., composting, solar drying, incineration are considered.

\section{Life Cycle Assessment for Uganda Christian University}

The overall goal of this LCA was to assess the environmental impact associated with the management of various organic waste streams using different integrated sanitation system alternatives proposed for UCU. In this LCA, the environmental impact from only the operational stage of the sanitation system alternatives was considered since the environmental impacts from replacement of equipment and construction of facilities have been reported to contribute minimally to the overall impact [29, 30]. The LCA was performed using Gabi 6 professional software, which enables assessments for the purpose of supporting design for the environment, eco-efficiency, eco-design and efficient value chains $[29,31]$.

\section{Functional Unit}

The Functional Unit (FU) basically provides a reference to which the inputs and outputs of the product or system can be related during the assessment [21, 32]. With reference to LCAs for waste management, it is often the case that the functional unit is defined in terms of the system's input, i.e., the waste. Thus, in this LCA comparison of different sanitation systems providing the same service of management of organic waste streams was considered [33].

The FU applied in this study was the management of 897 tons of organic waste by the sanitation system alternatives proposed. The FU corresponded to the estimated amount of organic waste generated annually from UCU. To enable the assessment, definition of the sanitation system boundaries is very crucial. Thus with reference to the local context at UCU, six sanitation systems were proposed and are described as follows in chapters below.

\section{Sanitation system alternatives}

The Status Quo alternative represents the current sanitation system at UCU with a few modifications. This sanitation system consists of pumping sewage sludge from the WWTP to a gravity settling tank, where dewatering of the Sewage sludge (Os) takes place prior to partial stabilization of the sewage sludge in the lagoons. Moreover, $30 \%$ of the partially stabilized sewage sludge from the lagoons is used as soil conditioner, while $70 \%$ of the residual sewage sludge is left to accumulate in the lagoons. Other considerations within this system boundary include: utilization of Food waste (Fw) from the kitchen as animal feed and application of Cow dung $(\mathrm{Cd})$ from the University farm in nearby gardens or dumping the dung in the animal kraal.

The Composting and Anaerobic Digestion (COMPAD) sanitation system consists of pumping the sewage sludge from the WWTP to a gravity settling tank prior to partial stabilization of sewage sludge in the lagoon. Thereafter, co-composting of the sewage sludge from the lagoon with other organic waste, i.e., wood shavings from carpentry, portion of kitchen waste, was considered and the compost generated would be utilized as soil conditioner. Furthermore, the pre-treatment of kitchen waste and mixing it with cow dung prior to anaerobic co-digestion in a vertical Continuous Stirred Tank Reactor (CSTR), operating at mesophilic conditions $\left(30-42{ }^{\circ} \mathrm{C}\right)$ was proposed. Utilization of biogas that would be produced from the AD process was examined with reference to two scenarios, i.e., direct utilization of the Biogas as cooking fuel (BfC) or for Cogeneration (CoGen) of electricity and heat from a Combined Heat and Power (CHP) unit. 
CHP specifications included at least $50 \mathrm{~kW}$ power rating with an overall efficiency of $83 \%$, i.e., an electricity conversion of $31 \%$ and heat output of $52 \%$. Meanwhile, the application of digestate generated from the $\mathrm{AD}$ process as organic fertilizer was also considered. Therefore, substitution of electricity from the national grid, thermal energy generated from firewood for cooking and mineral fertilizers used by local farmers were also considered within the COMPAD alternative boundary.

The Composting and Anaerobic Digestion-Landfill (COMPAD LF) sanitation system is similar to the COMPAD alternative with the exception that the co-composting process of sewage sludge and organic waste would be carried out at Mukono Municipal landfill in contrast to UCU campus. Thus, transportation of the partially stabilized sewage sludge to Mukono Municipal landfill located about $7 \mathrm{~km}$ away from the University campus was included within the boundary. Meanwhile, the AD process would take place at UCU and handling of biogas and digestate would be as described for the COMPAD system.

The Incineration and Anaerobic Digestion (INCAD) sanitation system consists of similar components to the COMPAD alternative with the exception of solar drying of the partially stabilized sewage sludge from the lagoon prior to co-incineration with other waste. Recovery of energy in form of waste heat would also be anticipated. Moreover, the AD process of cow dung and food waste would still be considered. Thus, all by-products from this, i.e., biogas and digestate would be managed in a similar manner to the COMPAD and COMPAD LF sanitation systems. Figure 2 below gives an overview of the three sanitation system alternatives described.

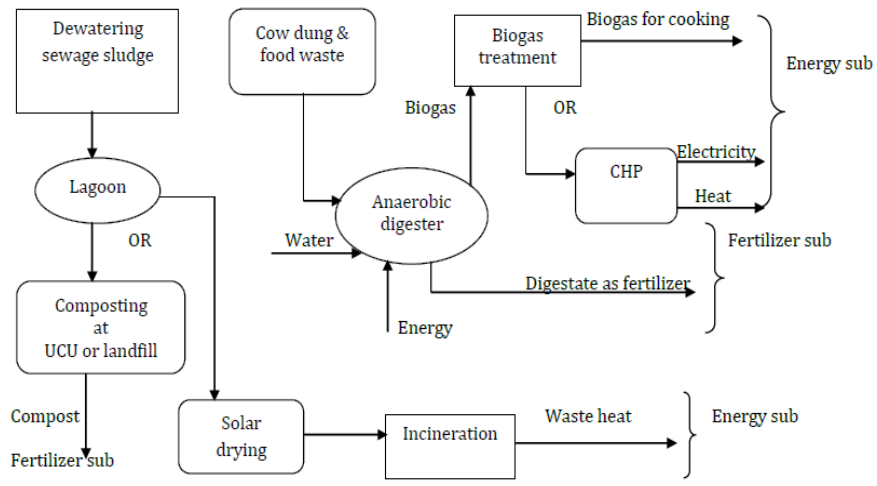

Figure 2. Overview of COMPAD, COMPAD LF, INCAD sanitation system boundaries

Other sanitation systems alternatives suggested include the integrated options as described.

The Integrated (INTEG 1) sanitation system consists of mixing sewage sludge from the WWTP with other substrates. Thus, pre-treatment of food waste prior to mixing it with cow dung and sewage sludge in the composition (Os:Cd:Fw $=30: 20: 50$ ) was considered. Effluent from the WWTP would also be used as process water for mixing the substrates. The substrate mixture would then be anaerobically digested, producing biogas and digestate. Biogas produced would be managed in a similar manner described for COMPAD, COMPAD LF and INCAD sanitation systems.

On the other hand, digestate from the digester would be directed to the lagoons where partial stabilization and dewatering is expected to take place prior to solar drying to improve the quality of the organic fertilizer produced. Thus, substitution of firewood, grid electricity and mineral fertilizer production processes were also considered within the INTEG 1 sanitation system boundary.

The Integrated 2 (INTEG 2) sanitation system was similar to the INTEG 1 alternative but also considered Faecal sludge (Fs) as an additional substrate anaerobically digested. Thus, a substrate mixture of composition Fs:Os:Cd:Fw $=10: 20: 20: 50$ was considered. Furthermore, $40 \%$ of the solar dried digestate was considered for briquette making while 
the remaining $60 \%$ would be used as organic fertilizer. The substituted processes taken into account for the INTEG 2 alternative were similar to those considered for INTEG 1. Moreover, substitution of firewood with briquettes made from digestate was additionally included. As earlier mentioned, two scenarios were considered for all the sanitation system alternatives which consisted of the $\mathrm{AD}$ process, i.e., utilization of $\mathrm{BfC}$ or $\mathrm{CoGen}$ of electricity and waste heat. Heat generated from the CoGen scenario could be used for heating the digester and heating water later utilized for cooking purposes.

In summary, for all sanitation system alternatives which consisted of an $\mathrm{AD}$ unit, substrate/feedstock are identified and pre-treated prior to AD. The by-products from the $\mathrm{AD}$ process would be managed variably, i.e., biogas and digestate.

Concurrently, partially stabilized sewage sludge could either be composted or incinerated, depending on the sanitation system alternative considered. Figure 3 gives an overview of the INTEG 1 and 2 sanitation system alternatives described.

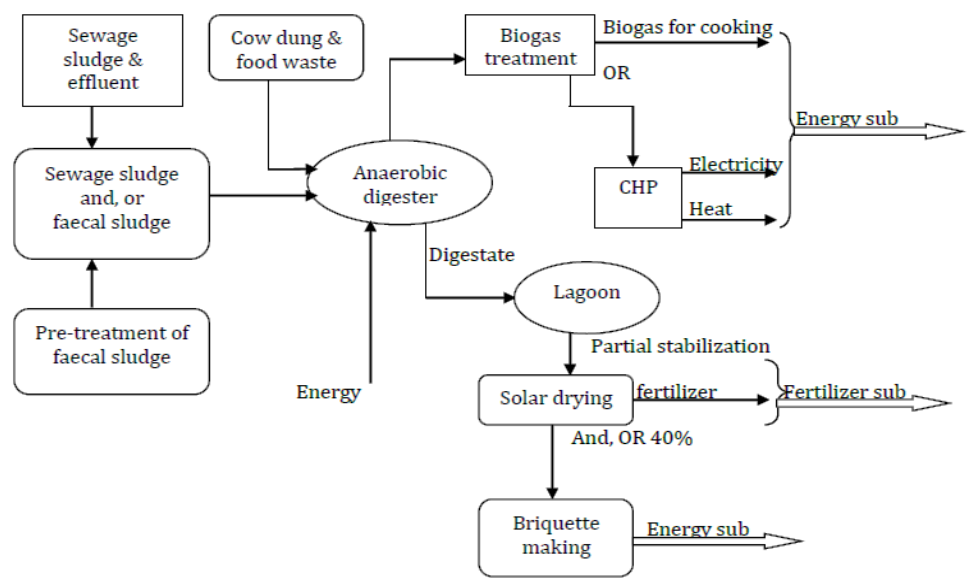

Figure 3. Overview of INTEG 1 and INTEG 2 sanitation system boundaries

With regards to the sanitation systems described, research has shown that after the AD process, digested sludge shows a high content of nutrients, primarily nitrogen and phosphorus. Hence sewage sludge can be used as a potential fertilizer source and soil conditioner [34, 35]. AD of sewage sludge allows for stabilization and degradation of biological contaminants such as pathogens and weed seeds to a great extent, although this may depend on process parameters such as temperature and the retention time inside the digester. Worthy of mention is that certain contaminants in sewage sludge may not be degraded at all. Such contaminants include physical contaminants, i.e., pieces of inert or larger pieces of digestible material and chemical contaminants, for instance heavy metals or complex organic pollutants (pharmaceuticals, surfactants, polyaromatic hydrocarbons). Based on fears regarding the persistent nature of heavy metals and complex organic pollutants in sewage sludge, certain developed countries such as USA, Japan and countries within the European Union have placed restrictions against recycling of sewage sludge as organic fertilizer [36, 37].

As a measure to check the presence of persistent contaminants in digestate, suggestions have been made to ensure selection of substrates or alternative conditioning of sewage sludge prior to AD. Moreover, selection of substrates such as sewage sludge used in the digester could be informed by carrying out preliminary quality tests, for example heavy metal content tests $[38,39]$. A similar stance was considered for the UCU scenario thus, quality tests were carried out on sewage sludge samples obtained from the lagoon at the WWTP. The results obtained were compared to international standards for cases when biosolids are considered for land application.

The laboratory analysis indicated that the composition of heavy metals in the sewage sludge obtained from UCU was below the ceiling concentrations stipulated by the United 
States Environment Protection Agency (EPA) and the European Commission (EC) standards. These results basically implied that the sewage sludge could be considered for land application. Table 1 shows a summary of the sewage sludge quality test carried out at Uganda Quality Assurance Laboratory.

Table 1. Summary of sewage sludge sample laboratory analysis

\begin{tabular}{cccc}
\hline Parameter & $\begin{array}{c}\text { Mean values } \\
\text { UCU sewage sample }\end{array}$ & $\begin{array}{c}\text { EPA ceiling concentration limits for } \\
\text { all biosolids applied on land }\end{array}$ & $\begin{array}{c}\text { EC ceiling concentration limits for } \\
\text { all biosolids applied on land }\end{array}$ \\
\hline Cadmium $[\mathrm{mg} / \mathrm{kg}]$ & $<0.001$ & 85 & $20-40$ \\
Copper $[\mathrm{mg} / \mathrm{kg}]$ & 7.501 & 4,300 & $1,000-1,750$ \\
Nickel $[\mathrm{mg} / \mathrm{kg}]$ & $<0.001$ & 420 & $300-400$ \\
Lead $[\mathrm{mg} / \mathrm{kg}]$ & $<0.001$ & 840 & $750-1,200$ \\
Zinc $[\mathrm{mg} / \mathrm{kg}]$ & 29.107 & 7,500 & $2,500-4,000$ \\
Potassium $[\mathrm{mg} / \mathrm{kg}]$ & 47.398 & & \\
Total nitrogen $[\mathrm{mg} / \mathrm{kg}]$ & 2.260 & & \\
Phosphorus $[\mathrm{mg} / \mathrm{kg}]$ & 4.900 & & \\
\hline Sources: Government Analytical Laboratory, $2016[40,41]$ &
\end{tabular}

Despite the low heavy metal content in the sewage sludge samples from UCU, the sanitation systems described are proposed for other entities such as cities, towns or even health facilities in Uganda. In such cases, high heavy metal content in wastewaters generated from sources including industries can be expected. Hence, other post treatment or management measures would be necessary. Case in point, once the AD sewage sludge has been carried out, the digestate could be dried prior to undergoing thermal treatment, i.e., incineration or pyrolysis processes.

The thermal processes mentioned basically help to fix the heavy metals in the ash or char prior to final disposal $[42,43]$. Moreover, research in line with managing heavy metal content in sewage sludge has also resulted in development of patents, where substances such as basaltic detritus has been used for heavy metals transformation in to slightly soluble compounds. Basaltic detritus acts like a natural sorbent and ionic exchanger with strong affinity for metal ions and its hydroxides. Besides, studies have also shown that production of organo-mineral fertilizers from sewage sludge has resulted in lower heavy metal content, especially when disinfection using alkali substances has been carried out [34, 44]. Thus, although assessment of the latter technologies/processes was not considered in this study, the various routes through which heavy metals in sewage sludge can be managed are recognized.

\section{Key assumptions and limitations}

The following assumptions and limitations were considered when carrying out this LCA.

\section{Assumptions}

- Organic waste streams were considered as inputs to the sanitation systems and were not followed upstream;

- Wastewater treatment at the WWTP was not considered, however, management of generated sludge, i.e., pumping and dewatering was included in system boundaries;

- Biogas leakages/emissions from the AD unit were assumed to be $7 \%$ of biogas generated. Such leakages could occur at various points, i.e., CHP unit, gas storage unit, along the piping and within the digestate storage unit $[45,46]$.

\section{Limitation}

For certain processes such as electricity and diesel production, data sets from Gabi 6 software were used. Although data sets from Africa were absent in the Gabi software, 
selection of the electricity and diesel processes used in the models was based on similarity to the Ugandan scenario. Thus, with regards to electricity mix, Norway electricity grid mix process was considered since it consisted of mainly hydropower, accountings for at least $83 \%$ of overall grid mix electricity as is the case in Uganda. Meanwhile, the diesel processes from India were considered in the models since they were similar to those from Uganda [31]. Despite considering closely similar data sets from the software for the models, utilization of process data sets specific to the Africa region could cater for any variability that may exist in technological processes applied in specific local contexts. Thus absence of regional (Africa) specific data in Gabi 6 software was considered a limitation.

\section{Life cycle inventory}

The inventory phase involved data collection and calculation procedures for quantification of relevant inputs and outputs of the sanitation systems with reference to the FU. Thus, computation of the raw materials that would be consumed, energy used and potential emissions to environment for all sanitation systems was carried out.

Locally, data was compiled from UCU and this included information related to sewage sludge pumping from the WWTP, quantities of organic waste generated, distances covered in case of waste transportation, etc. Also, relevant data from literature, publications and government documents was obtained to support the assessment. Moreover, data for processes such as electricity grid mix, thermal energy from firewood, mineral fertilizer production, transportation, incineration and landfilling modeled for the various sanitation system scenarios was obtained from Gabi 6 Professional database. Noteworthy was that during inventory computations, the potential Carbon dioxide $\left(\mathrm{CO}_{2}\right)$ emitted during utilization of firewood for cooking was counted as biogenic. Thus, $\mathrm{CO}_{2}$ emitted from these processes was considered to have zero impact to climate as suggested in Intergovernmental Panel for Climate Change (IPCC) guidelines [47, 48]. Furthermore, upstream processes related to collection and transportation of firewood were excluded from the system boundaries and inventory computations respectively. Table 2 shows the overall life cycle inventory of main flows for respective sanitation systems.

Table 2. Shows the life cycle inventory of the main flows to sanitation system alternatives

\begin{tabular}{|c|c|c|c|c|c|c|c|c|c|}
\hline Waste treatment & Flow & $\begin{array}{l}\text { Status } \\
\text { Quo }\end{array}$ & COMPAD & $\begin{array}{l}\text { COMPAD } \\
\text { LF }\end{array}$ & INCAD & INTEG 1 & INTEG 2 & $\begin{array}{c}\text { Units } \\
\text { (per ton } \\
\text { of waste) }\end{array}$ & Source \\
\hline \multicolumn{10}{|c|}{ Sludge pumping } \\
\hline Energy consumption & Electricity & 0.203 & 0.203 & 0.203 & 0.203 & 0.203 & 0.203 & {$[\mathrm{kWh}]$} & Calculated \\
\hline \multicolumn{10}{|c|}{ Composting } \\
\hline & Nitrogen $(\mathrm{N})$ & & 0.55 & 0.55 & & & & {$[\mathrm{~kg}]$} & Literature \\
\hline & $\begin{array}{l}\text { Phosphorus pentoxide } \\
\qquad\left(\mathrm{P}_{2} \mathrm{O}_{5}\right)\end{array}$ & & 1.9 & 1.9 & & & & {$[\mathrm{~kg}]$} & Literature \\
\hline & Potassium oxide $\left(\mathrm{K}_{2} \mathrm{O}\right)$ & & 6.4 & 6.4 & & & & {$[\mathrm{~kg}]$} & Literature \\
\hline \multicolumn{10}{|c|}{ Pretreatment } \\
\hline Energy consumption & Electricity & & 1.289 & 1.289 & 1.289 & 1.289 & 1.289 & [kWh] & Calculated \\
\hline \multirow[b]{2}{*}{ Water } & Fresh water & & $1,693.2$ & $1,693.2$ & $1,693.2$ & & & [L] & Calculated \\
\hline & $\begin{array}{c}\text { Effluent } \\
\text { (process } \mathrm{H}_{2} \mathrm{O} \text { ) }\end{array}$ & & - & & - & 361.3 & 484.3 & {$[\mathrm{~L}]$} & Calculated \\
\hline \multicolumn{10}{|c|}{$\mathrm{AD}$} \\
\hline Energy consumption & Electricity & & 34 & 34 & 34 & 34 & 34 & [kWh] & Literature \\
\hline \multirow{4}{*}{ Valuable materials } & Digestate & & $1,404.7$ & $1,404.7$ & $1,404.7$ & $1,606.74$ & 2,527 & {$[\mathrm{~kg} /$ day $]$} & Calculated \\
\hline & Biogas & & 263.6 & 263.6 & 263.6 & 350.6 & 493.4 & {$\left[\mathrm{Nm}^{3} /\right.$ day $]$} & Calculated \\
\hline & Methane $\left(\mathrm{CH}_{4}\right)$ & & 60 & 60 & 60 & 60 & 60 & {$[\%]$} & Literature \\
\hline & $\mathrm{CO}_{2}$ & & 40 & 40 & 40 & 40 & 40 & [\%] & Literature \\
\hline Gaseous leakages & Biogas & & 10 & 10 & 10 & 10 & 10 & [\%] & Estimated \\
\hline \multicolumn{10}{|c|}{ Lagoon-digestate } \\
\hline \multirow{2}{*}{ Valuable materials } & NPK fertilizer & & 17.05 & 17.05 & 9.89 & 4.64 & 4.03 & {$[\mathrm{~kg}]$} & Estimated \\
\hline & Briquettes & & & & & & 378.5 & {$[\mathrm{~kg}]$} & Calculated \\
\hline \multicolumn{10}{|c|}{ CHP unit } \\
\hline & Electricity & & 441.3 & 441.3 & 441.3 & 587 & 826 & [kWh/day] & Calculated \\
\hline & Thermal energy & & 740.2 & 740.2 & 740.2 & 984.7 & $1,385.5$ & [kWh/day] & Calculated \\
\hline
\end{tabular}




\section{Life cycle impact assessment}

This stage of the LCA aims at assessing the life cycle inventory to better understand the environmental significance of the sanitation systems. Thus, assessment of the environmental impacts arising from the life cycle inventory was carried out. To accomplish this task, environmental impact categories were assigned for the inputs and outputs to the sanitation systems. The impact category indicators were then used to explain the inventory results. As such, the mandatory steps which include classification and characterization of the impact categories was carried out using the CML 2001 impact assessment methodology in Gabi 6 software [21,31]. Given that no agreed universal list of impact categories exists for carrying out such LCAs, the following set was selected; Global Warming (GWP), Eutrophication Potential (EP) and Human Toxicity Potential (HTP). The choice of the impact categories was influenced by the anticipated impacts from improper management of the organic waste streams and the potential resource use as well as recovery from system's operation phase considered. Besides, the available impact categories in the Gabi 6 software also influenced the final choice of impact categories.

\section{DISCUSSION OF RESULTS}

The results from computation of the environmental impact for the six sanitation system alternatives are summarized in Table 3 . In general, negative or lower impact values represent an environmentally beneficial sanitation system, while positive or higher impact values represent environmental burdens from the respective sanitation systems. The results indicated that for all sanitation system alternatives which consisted of AD process, much lower impact values were registered in comparison to the Status Quo. Meanwhile, the trend of performance for the different sanitation system alternatives varied with reference to specific impact categories and the results are summarized in Table 3.

Table 3. Shows the environmental impact results for sanitation system alternatives with reference to the FU

\begin{tabular}{|c|c|c|c|c|c|c|c|c|c|c|c|c|}
\hline \multirow{2}{*}{ Impact } & \multirow{2}{*}{ Units } & \multirow{2}{*}{$\begin{array}{c}\text { Status } \\
\text { Quo }\end{array}$} & \multicolumn{2}{|c|}{ COMPAD } & \multicolumn{2}{|c|}{ COMPAD LF } & \multicolumn{2}{|c|}{ INCAD } & \multicolumn{2}{|c|}{ INTEG 1} & \multicolumn{2}{|c|}{ INTEG 2} \\
\hline & & & $\mathrm{BfC}$ & CoGen & $\mathrm{BfC}$ & CoGen & $\mathrm{BfC}$ & CoGen & $\mathrm{BfC}$ & CoGen & BfC & CoGen \\
\hline GWP & {$\left[\mathrm{kg} \mathrm{CO}_{2} \mathrm{eq}\right]$} & $3.27 \mathrm{E}+5$ & $4.18 \mathrm{E}+4$ & $4.36 \mathrm{E}+4$ & $4.16 \mathrm{E}+4$ & $4.33 \mathrm{E}+4$ & $1.35 \mathrm{E}+5$ & $1.35 \mathrm{E}+5$ & $3.93 \mathrm{E}+4$ & $4.04 \mathrm{E}+4$ & $4.47 \mathrm{E}+4$ & $4.45 \mathrm{E}+4$ \\
\hline $\mathrm{EP}$ & {$\left[\mathrm{kg} \mathrm{PO}_{4}^{-3} \mathrm{eq}\right]$} & $2.58 \mathrm{E}+2$ & $6.83 \mathrm{E}+1$ & $8.18 \mathrm{E}+1$ & $6.83 \mathrm{E}+1$ & $8.18 \mathrm{E}+1$ & $8.28 \mathrm{E}+1$ & $8.96 \mathrm{E}+1$ & $7.71 \mathrm{E}+1$ & $8.63 \mathrm{E}+1$ & $3.58 \mathrm{E}+1$ & $3.88 \mathrm{E}+1$ \\
\hline HTP & [kg DCB eq] & $1.71 \mathrm{E}+4$ & $1.45 \mathrm{E}+4$ & $1.68 \mathrm{E}+4$ & $1.45 \mathrm{E}+4$ & $1.68 \mathrm{E}+4$ & $1.30 \mathrm{E}+4$ & $1.38 \mathrm{E}+4$ & $1.57 \mathrm{E}+4$ & $1.69 \mathrm{E}+4$ & $7.56 \mathrm{E}+3$ & $7.50 \mathrm{E}+3$ \\
\hline
\end{tabular}

\section{Global Warming Potential}

The Status Quo sanitation system registered the highest GWP value followed by INCAD, INTEG 2, COMPAD, COMPAD LF while INTEG 1 alternative performed best, registering the least GWP value. A summary of processes contribution to GWP and the respective emissions from the sanitation systems is represented in Table 4. Moreover, for the sanitation systems which consisted of the AD unit, significant reduction in GWP was attained when substitution of firewood with biogas as a cooking fuel was considered and this accounted for a reduction in GWP of upto $-1,340 \mathrm{~kg} \mathrm{CO} 2$ eq. Meanwhile, the substitution of artificial fertilizer with compost and digestate as organic fertilizer contributed to reduction in GWP of at least $-1,210 \mathrm{~kg} \mathrm{CO}_{2}$ eq.

Table 4. Shows a summary of process contribution to GWP

\begin{tabular}{ccc}
\hline Sanitation system & Process contribution to GWP [\%] & Respective emissions \\
\hline Status Quo & Dumping of residual sewage sludge (LDS) [97\%] & $\mathrm{CH}_{4}$ emissions \\
COMPAD, COMPADLF, & AD (68\%) & $\mathrm{CH}_{4}$ \\
INTEG 1, INTEG 2 & Utilization of Firewood for Cooking (UFc) (20.8\%) & $\mathrm{CO}_{2}$ \\
\hline
\end{tabular}




\section{Eutrophication Potential}

The performance trend of the sanitation systems with reference to EP indicated that the INTEG 2 system registered the least value followed by COMPAD and COMPAD LF, INTEG 1, INCAD and finally the Status Quo. The summary of process contribution to EP by the respective sanitation systems is included in Table 5. Moreover, significant reduction in substances contributing to EP was registered when substitution of firewood for cooking with briquettes and biogas was considered. This was mainly the case for the INTEG 2, COMPAD/COMPAD LF and INCAD sanitation systems. Utilization of briquettes in contrast to firewood accounted for up to $-43.5 \mathrm{~kg} \mathrm{PO}_{4}{ }^{-3}$ eq reduction, while utilization of biogas for cooking accounted for $-12.3 \mathrm{~kg} \mathrm{PO}_{4}^{-3}$ eq reduction in the EP.

Table 5. Summary of process contribution to EP

\begin{tabular}{ccc}
\hline Sanitation systems & Process contribution to EP [\%] & Respective emissions \\
\hline Status Quo & LDS (69\%) & Ammonia $\left(\mathrm{NH}_{3}\right)$ emissions \\
Nitrogen oxides $\left(\mathrm{NO}_{\mathrm{x}}\right)$ and $\mathrm{NH}_{3}$ \\
$\begin{array}{c}\text { COMPAD, COMPAD LF, } \\
\text { INTEG1, INTEG 2 }\end{array}$ & UFc $(90 \%)$ & $\mathrm{NO}_{\mathrm{x}}$ \\
\hline
\end{tabular}

\section{Human Toxicity Potential}

With reference to HTP, the trend of performance showed that INTEG 2 registered the least value followed by INCAD, COMPAD and COMPAD LF, INTEG 1 and finally Status Quo. For all the sanitation system alternatives consisting of the AD process, UFc purposes dominantly accounted for at least $90 \%$ HTP. The main emission to air from this process was Hydrogen Fluoride (HF) gas. Significant reduction in substances contributing to HTP was registered mainly from briquette and biogas utilization instead of firewood for cooking purposes. Moreover, due to the emission control measures incorporated in the incineration unit process, significant reduction in substances contributing to HTP was registered for the INCAD sanitation system as well. Thus, INTEG 2 and INCAD showed significant reduction in HTP of at least $-9.68 \mathrm{E}+03 \mathrm{~kg}$ DCB eq and $-3.44 \mathrm{E}+03 \mathrm{~kg}$ DCB eq, respectively.

Overall, the results highlighted the much better environmental performance for all sanitation systems which additionally consisted of the AD process in comparison to the Status Quo alternative. These results concurred with other LCA studies for sewage sludge and organic waste management, which indicated that application of AD for management of similar waste streams improved system environmental performance due to resource recovery $[16,50]$. Moreover, for sanitation systems which consisted of AD, lower environmental burden was noted when the BfC scenario was considered in comparison to CoGen scenario.

This suggested that utilization of BfC maybe more environmentally friendly than utilization of biogas for CoGen. However, a decision in favour of such a suggestion would be dependent on the priorities of UCU with regards to utilization of the biogas generated.

With respect to specific impact categories, variable performance trends were registered, i.e., GWP performance trend indicated INTEG $1>$ COMPAD LF > COMPAD > INTEG $2>$ INCAD $>$ Status Quo. The system performance trend with reference to EP was INTEG $2>$ COMPAD/COMPAD LF $>$ INTEG $1>$ INCAD $>$ Status Quo. Finally, the system performance trend with respect to HTP showed that INTEG $2>$ INCAD > COMPAD/COMPAD LF > INTEG $1>$ Status Quo. The most dominant processes which contributed to GWP were AD, utilization of firewood as cooking fuel, dumping of partially stabilized sewage sludge and incineration of waste. Meanwhile, UFc dominantly contributed to EP and HTP impact categories. The significant 
contribution of firewood utilization highlighted the dependence on firewood use for cooking at UCU and this accounted for about $90 \%$ cooking energy demand. On the other hand, the significant contribution of AD process to GWP was mainly attributed to the biogas leakages/fugitive emissions from the anaerobic digester unit, which were assumed to be $7 \%$ of biogas generated. Moreover, $\mathrm{CH}_{4}$ from the fugitive emissions contributed most to GWP since $\mathrm{CO}_{2}$ emissions were considered biogenic and yet $\mathrm{CH}_{4}$ accounts for GWP up to 28 times $\mathrm{CO}_{2}$ equivalent for a 100 year time horizon [47].

Resource recovery processes which contributed to lower environmental burden included: substitution of firewood with biogas and, or briquettes for cooking purposes, substitution of electricity from national grid with electricity generated from the CHP unit and substitution of mineral fertilizer with compost or organic fertilizer from compost and digestate. The avoided emissions due to resource recovery influenced the overall environmental performance of respective sanitation systems. Taking into consideration all impact categories, the assessment of environmental feasibility for the sanitation systems indicated that the INTEG 2 alternative registered the least overall impact followed by the COMPAD LF, then COMPAD, INTEG 1, INCAD and finally Status Quo alternative. The results showed a direct correlation between resource recovery and environmental feasibility as justified by the good environmental performance registered by the INTEG 2 alternative. The avoided emissions due to substitution of firewood use with biogas and briquettes made from digestate contributed to the much lower environmental impact of the INTEG 2 alternative. These results also concurred with findings from a study by Pilusa et al. [51] who determined that emissions from eco-briquettes were minimal and conformed to the Occupational Safety and Health Agency (OSHA) exposure standards. As such, additional resource recovery, i.e., utilization of dried digestate as a fuel could be an attractive venture for similar sanitation systems $[52,53]$.

Having identified key environmental assessment hot spots highlighted by the significant contribution of processes such as AD and utilization of firewood for cooking, a sensitivity analysis taking into consideration the INTEG 2 sanitation system was carried out. The analysis considered a reduction in fugitive emissions from $7 \%$ to $5 \%$ and finally $3 \%$. Furthermore, substitution of firewood with biogas and briquettes by varying the amount substituted between the range $-20 \%$ to $20 \%$ was carried out. The results indicated that a reduction in GWP of at least $27 \%$ was recorded when fugitive emissions were reduced to $5 \%$, while a $15 \%$ reduction in the GWP was registered when fugitive emissions were further reduced to $3 \%$.

Meanwhile, substitution of firewood with biogas for cooking resulted in a 5-8\% reduction for all impact categories. Finally, further substitution of firewood with briquettes for cooking resulted in at least $100 \%$ reduction in all impact categories. These results further confirmed that additional resource recovery contributed to lower environmental impact from the sanitation system.

\section{CONCLUSIONS}

The environmental assessment of the sanitation system alternatives proposed for UCU provides essential information which can be used to guide decision makers when selecting and eventually planning for sustainable organic waste management strategies at the University. Moreover, similar sanitation systems could be applied by other entities such as health institutions, housing estates, towns and cities which may have similar contexts to UCU or fulfill the criteria initially stipulated. The LCA results generally illuminate the fact that incorporation of processes/technologies such as $\mathrm{AD}$, composting, incineration and briquetting which boost resource recovery in the management of organic waste streams contribute to lower environmental impacts of the sanitation systems. This is because a direct correlation exists between resource recovery and the lower 
environmental impacts of sanitation systems. Thus, sanitation system alternatives which considered additional resource recovery also registered much lower environmental impact values as was the case for the INTEG 2 alternative.

Given that the local context is a crucial aspect of the integrated sanitation systems, design of variable systems can be expected for entities such as health/academic institutions, industries/factories, housing estates, peri-urban centres, towns and cities. Nevertheless, the challenge of managing variable organic waste streams from the different entities mentioned which could be influenced by the anticipated increase in urbanization in Uganda, thrusts integrated sanitation systems to the spotlight as viable options. In addition to reducing potential environmental and health impacts related to poor organic waste management, the integrated sanitation systems promote a sanitation-energy-agriculture nexus. Such a nexus makes management of organic waste streams from growing urban areas an attractive venture since various stakeholders would accrue benefits along the value chain, i.e., management of waste, resource recovery, job creation, etc. Therefore, it can be concluded that integrated sanitation systems are not only environmentally feasible, but could also constitute part of the solution to organic waste management challenges in urban areas of Uganda and other Sub-Saharan countries with similar contexts.

\section{ACKNOWLEDGMENT}

The authors gratefully acknowledge the financial support from Schlumberger Faculty for the Future Foundation for funding this research and Uganda Christian University for the assistance accorded during the PhD research on which this paper is based.

\section{REFERENCES}

1. Fachverband Biogas, German Biogas Association, Biowaste to Biogas, Biogas Know How 1, 2017.

2. Hoornweg, D. and Bhada-Tata, P., What a Waste: A Global Review of Solid Waste Management, World Bank, Washington, USA, 2012.

3. Ministry of Water and Environment (MoWE), Government of Uganda, Water and Environment Sector Performance Report, 2016.

4. Schoebitz, L., Niwagaba, C. B. and Strande, L., SFD Promotion Initiative: Kampala, Uganda, 2016.

5. Sippel, L., Africa's Demographic challenges: How a young Population can make development possible, Berlin Institute for Population and Development, Berlin, Germany, 2011.

6. Ministry of Water and Environment (MoWE), Government of Uganda, Water and Environment Sector Performance Report, 2017.

7. Cleland, J. and Machiyama, K., The challenges posed by demographic change in Sub-Saharan Africa: A concise Overview, Population and Development Review, Vol. 43, No. S1, pp 264-286, 2017, https://doi.org/10.1111/padr.170

8. Parkinson, J., Lüthi, C. and Walther, D., Sanitation21 - A Planning Framework for Improving City-wide Sanitation Services, IWA, Eawag-Sandec, GIZ, 2014.

9. Anderson, K., Rosemarin, A., Lamizana, B., Kvarnström, E., McConville, J., Seidu, R., Dickin, S. and Trimmer, C., Sanitation, Wastewater Management and Sustainability: From Waste Disposal to Resource Recovery, Nairobi and Stockholm: United Nations Environment Programme and Stockholm Environment Institute, Nairobi, Kenya, 2016.

10. Water and Environmental Health at London and Loughborough (WELL), Guidance Manual on Water Supply and Sanitation Programmes, Department for International Development, London, UK, 1998. 
11. Water Supply and Sanitation Collaborative Council (WSSCC) and World Health Organization (WHO), Sanitation and Hygiene Promotion: Programming Guidance, 2005.

12. EAWAG, Department of Sanitation, Water and Solid Waste for Development, Summary Report of Bellagio Expert consultation on Environmental Sanitation in the $21^{\text {st }}$ Century, 2000.

13. Lüthi, C., McConville, J., Norström, A., Panesar, A., Ingle, R., Saywell, D. and Schütze, T., Rethinking sustainable Sanitation for the Urban Environment, Conference Paper, $4^{\text {th }}$ International Conference of the International Forum on Urbanism, Delft, Netherlands, 2009.

14. United Nations International Children's Emergency Fund (UNICEF), Generating Energy with Biogas Latrines in Schools in Uganda, Case Study, 2014.

15. Parkes, O., Lettieri, P., David, I. and Bogle, L., Life Cycle assessment of integrated Waste management Systems for alternative legacy Scenarios of the London Olympic Park, Waste Management, Vol. 40, pp 157-166, 2015, https://doi.org/10.1016/j.wasman.2015.03.017

16. Chiu, S. L. H., Lo, I. M. C., Woon, K. S. and Yan, D. Y. S., Life Cycle assessment of Waste treatment Strategy for Sewage Sludge and Food Waste in Macau: Perspectives on Environmental and Energy production performance, Int. J. Life Cycle Assess., Vol. 21, No. 2, pp 176-189, 2016, https://doi.org/10.1007/s11367-015-1008-2

17. Ocwieja, S. M., Life Cycle thinking assessment applied to three Biogas Projects in Central Uganda, M.Sc. Thesis, Michigan Technological University, Michigan, USA, 2010.

18. Komakech, A. J., Zurbrügg, C., Miito, G. J., Wanyama, J. and Vinnerås, B., Environmental impact from Vermicomposting of Organic Waste in Kampala, Uganda, Journal of Environmental Management, Vol. 181, pp 395-402, 2016, https://doi.org/10.1016/j.jenvman.2016.06.028

19. United Nations (UN), Transforming our World: The 2030 Agenda for Sustainable development, 2015.

20. Helias, A., Des Haes, U., van Rooijen, M., Saur, K., Norris, G., Jolliet, O. and Sonnemann, G., Life Cycle approaches: The Road from analysis to Practice, UNEP \& Life Cycle Initiative, 2005.

21. International Organization for Standardization (ISO), Environmental managementLife Cycle assessment- Principles and Framework, 1997.

22. International Reference Life Cycle Data System (ILCD) Handbook, Framework and Requirements for Life Cycle Impact Assessment Models and Indicators, Publications Office, Luxembourg, Luxembourg, 2010.

23. United Nations Environment Programme/Society of Environmental Toxicology and Chemistry (UNEP/SETAC), Global Guidance for Life Cycle impact assessment Indicators, 2016.

24. Chirjiv, K. A., Evaluation of conventional and alternative Sanitation Technologies using the Life Cycle assessment approach, Ph.D. Thesis, Ohio, USA, 2013.

25. Risch, E., Gutierrez, O., Roux, P., Boutin, C. and Corominas, L., Life Cycle assessment of Urban Wastewater Systems: Quantifying the relative contribution of Sewer Systems, Water Research, Vol. 77, pp 35-48, 2015, https://doi.org/10.1016/j.watres.2015.03.006

26. Yin, R. K., Case Study Research: Design and Methods, SAGE, Los Angeles, California, USA, 2014.

27. Uganda Christian University, Strategic Plan 2012-2018, Kampala, Uganda, 2012.

28. Strande, L., Ronteltap, M. and Brdjanovic, D., Faecal Sludge management: Systems Approach for Implementation and Operation, International Water Association: IWA, London, UK, 2014. 
29. Remy, C., Life Cycle assessment of conventional and Source-Separation Systems for Urban Wastewater Management, Ph.D. Thesis, Technical University of Berlin, Berlin, Germany, 2010, https://doi.org/10.14279/depositonce-2370

30. Alyaseri, I. and Zhou, J., Towards better Environmental performance of Wastewater Sludge treatment using endpoint approach in LCA Methodology, Heliyon, Vol. 3, No. 3, 2017, https://doi.org/10.1016/j.heliyon.2017.e00268

31. PE International, Gabi Paper Clip Tutorial, 2011.

32. Jensen, A. A., Hoffman, L., Møller, B. T., Schmidt, A., Christiansen, K. and Elkington, J., Life Cycle Assessment (LCA): A Guide to Approaches, Experiences and Information Sources, Environmental Issue Report No. 6, 1997.

33. Cherubini, F., Bargigli, S. and Ulgiati, S., Life Cycle Assessment (LCA) of Waste management Strategies: Landfilling, Sorting Plant and Incineration, Energy, Vol. 34, No. 12, pp 2116-2123, 2009, https://doi.org/10.1016/j.energy.2008.08.023

34. Deeks, L. K., Chaney, K., Murray, C., Sakrabani, R., Gedara, S., Le, M. S., Tyrrel, S., Pawlett, M., Read, R. and Smith, G. H., A new Sludge-derived Organo-mineral Fertilizer gives similar Crop yields as conventional Fertilizers, Agron. Sustain. Dev., Vol. 33, No. 3, pp 539-549, 2013, https://doi.org/10.1007/s13593-013-0135-z

35. Kahiluoto, H., Kuisma, M., Ketoja, E., Salo, T. and Heikkinen, J., Phosphorus in Manure and Sewage Sludge more recyclable than in soluble inorganic Fertilizer, Environ. Sci. Technol., Vol. 49, No. 4, pp 2115-2122, 2015, https://doi.org/10.1021/es503387y

36. Christodoulou, A. and Stamatelatou, K., Overview of Legislation on Sewage Sludge management in developed Countries worldwide, Water Science and Technology, Vol. 73, No. 3, pp 453-462, 2016, https://doi.org/10.2166/wst.2015.521

37. Kirchmann, H., Börjesson, G., Kätterer, T. and Cohen, Y., From Agricultural use of Sewage Sludge to Nutrient extraction: A Soil Science Outlook, Ambio, Vol. 46, No. 2, pp 143-154, 2017, https://doi.org/10.1007/s13280-016-0816-3

38. Drosg, B., Fuchs, W., Al Sedi, T., Madsen, M. and Linke, B., Nutrient recovery by Biogas digestate processing, Technical Report, IEA Bioenergy, 2015.

39. Al Seadi, T., Rutz, D., Prassl, H., Köttner, M. and Finsterwalder, T., Biogas Handbook, University of Southern Denmark Esbjerg, Esbjerg, Denmark, 2008.

40. Environmental Protection Agency (EPA), Land application of Sewage Sludge: A Guide for Land appliers on the requirements of the Federal Standards for the use or disposal of Sewage Sludge, 40 CFR Part 503, 1994.

41. European Commission (EC), Disposal and recycling Routes for Sewage Sludge (Part 2), Regulatory Report, 2001.

42. Raheem, A., Sikarwar, V. S., He, J., Dastyar, W., Dionysiou, D. D., Wang, W. and Zhao, M., Opportunities and challenges in sustainable treatment and Resource reuse of Sewage Sludge: A Review, Chemical Engineering Journal, Vol. 337, pp 616-641, 2018, https://doi.org/10.1016/j.cej.2017.12.149

43. Evans, T. D., Review of current Knowledge: Sewage Sludge, Foundation of Water research, 2016.

44. Kominko, H., Gorazda, K. and Wzorek, Z., The possibility of Organo-Mineral fertilizer production from Sewage Sludge, Waste and Biomass Valorization, Vol. 8, No. 5, pp 1781-1791, 2017, https://doi.org/10.1007/s12649-016-9805-9

45. Jonerholm, K. and Lundborg, H., Methane losses in the Biogas System, Stockholm, Sweden, 2012.

46. Jørgensen, L. and Kvist, T., Methane emission from Danish Biogas Plants: Quantification of Methane losses, Project Report, Danish Gas Technology Centre, Hørsholm, Denmark, 2015. 
47. Intergovernmental Panel for Climate Change (IPCC), Guidelines for National Greenhouse Gas Inventories, Agriculture, Forestry and other Land use, Emissions from Livestock and Manure management, Vol. 4, 2006.

48. Environmental Protection Agency (EPA), Accounting Framework for Biogenic $\mathrm{CO}_{2}$ emissions from Stationary Sources, Published Report, 308343, 2011.

49. Wrap, Compost Calculator, 2016 , http://www.wrap.org.uk/content/compost-calculator, [Accessed: 10-October-2016]

50. Righi, S., Oliviero, L., Pedrini, M., Buscaroli, A. and Della Casa, C., Life Cycle assessment of management Systems for Sewage Sludge and Food Waste: Centralized and decentralized approaches, Journal of Cleaner Production, Vol. 44, pp 8-17, 2013, https://doi.org/10.1016/j.jclepro.2012.12.004

51. Pilusa, T. J., Huberts, R. and Muzenda, E., Emissions analysis from combustion of Eco-fuel Briquettes for domestic Applications, Journal of Energy in Southern Africa, Vol. 24, No. 4, 2013.

52. Kratzeisen, M., Starcevic, N., Martinov, M., Maurer, C. and Müller, J., Applicability of Biogas digestate as Solid Fuel, Fuel, Vol. 89, No. 9, pp 2544-2548, 2010, https://doi.org/10.1016/j.fuel.2010.02.008

53. Gardoni, D., and Guarino, M., Drying and combustion of an Anaerobic digestate: Results and Economical evaluation of a demonstrative-scale Plant, International Journal of Engineering Research \& Science, Vol. 2, No. 8, pp 2395-6992, 2016. 